\title{
THEORETICAL STUDY OF UNIAXIAL FLEXURAL BEHAVIOR OF ULTRA HIGH- PERFORMANCE REINFORCED CONCRETE BEAMS
}

\author{
Wael M. Montaser \\ Associate Professor, Building and Construction Department, \\ October 6 University, Cairo, Egypt \\ Ayman Hussein Hosny Khalil \\ Professor, Reinforced Concrete Structures, Structural Engineering Department, \\ Ain Shams University, Cairo, Egypt
}

Ahmed A. Abdel-Bary

M.Sc. Student, Structural Engineering Department, Ain Shams University, Cairo, Egypt

\begin{abstract}
Ultra high-performance concrete (UHPC) is an advanced cementitious composite consisting of a dense high strength matrix and fibers. The use of UHPC is growing worldwide owing to its high performance so leading to be employed in a wide range of practical applications like nuclear waste containment structures, high rise structures, long span bridges and thin shells. Studies on UHPC concentrated on special concrete materials with characteristics that differ from those of normal strength concrete at the material level. However, a few researches are available on the uniaxial flexural capacity of UHPC beams at the structural level that can predict the overall performance. This paper provides theoretical study for structural behavior of UHPC beams with different parameters. Parameters are: reinforcement ratio, concrete compressive strength, eccentricity ratio (e/t) and concrete cover. Eighteen finite element models were developed and analyzed in ANSYS software to investigate the effect of mentioned parameters on uniaxial flexural behavior of UHPC simple beams. The results showed that increasing the reinforcement ratio from 0.3 to $3 \%$ led to increase in flexure capacity by $541 \%$ and stiffness by $173 \%$. Increasing the concrete compressive strength from 115 to $215 \mathrm{MPa}$ led to increase in the stiffness by $9.32 \%$. While, the flexure capacity wasn't affected. Increasing the eccentricity ratio (e/t) from 0.50 to $\infty$ led to decrease in flexure capacity by $49.7 \%$ and stiffness by $49.8 \%$. Increasing the concrete cover from 30 to $70 \mathrm{~mm}$ led to decrease in flexure capacity by $17.2 \%$ and stiffness by $30.6 \%$. The FEM and results of this study provide valuable
\end{abstract}


data that can be used in future studies on the development of computational models of uniaxial flexural behavior of UHPC.

Keywords: Ultra high-performance concrete (UHPC), Structural, Uniaxial, ANSYS, Flexure capacity, Stiffness.

Cite this Article: Wael M. Montaser, Ayman Hussein Hosny Khalil and Ahmed A. Abdel-Bary, Theoretical Study of Uniaxial Flexural Behavior of Ultra HighPerformance Reinforced Concrete Beams. International Journal of Civil Engineering and Technology, 11(5), 2020, pp. 67-83.

https://iaeme.com/Home/issue/IJCIET?Volume $=11 \&$ Issue $=5$

\section{INTRODUCTION}

Concrete is currently the most building material worldwide. There are still some limitations related to the use of normal strength concrete, such as low tensile strength, almost no ductility and low range of compressive strength. High performance concrete is a material that can maximize the advantages of concrete due to its high compressive strength up to $100 \mathrm{MPa}$ but it shows less ductility than normal strength concrete. UHPC may be able to overcome ordinary concrete limitations. This is attributed to its better properties such as high tensile strength, high compressive strength, better ductility and low permeability compared to normal strength concrete.

The Association Française de Génie Civil (AFGC) [1] classified UHPC as having a compressive strength greater than $150 \mathrm{MPa}$ and internal fiber reinforcement to ensure non brittle behavior and high binder content with special aggregates. The US Army Engineering Research and Development Center (ERDC) [2] classified UHPC as cementitious materials with compressive strengths ranging from 138 to $276 \mathrm{MPa}$. Bratislav Lukic et al. [3] produced UHPC with compressive strength equal to $200 \mathrm{MPa}$. UHPC can make uniform stress distribution at the matrix, which can reduce potential for shear and tensile cracking at the interface. In addition to reduce the w/c typically close to 0.20 compared with a w/c ratio of 0.30-0.50 for conventional concrete [4].

Many types of UHPC have been developed and the main differences between them is the type and amount of fibers used and existence of coarse aggregates. The four main types of UHPC are Ceracem/BSI, compact reinforced composites (CRC), multi-scale cement composite (MSCC) and reactive powder concrete (RPC) [5]. Most common type of UHPC is RPC with steel fibers occupy two percent of the concrete mixture by volume [6]. Increasing the volume of fibers led to enhance the ductility and increase the bending strength [7]. Also the tensile strength of UHPC increased with increasing the volume of fibers [8]. Enhancements in flexural strength and energy absorption capacity were observed when longer fibers used [9].

In Hwan et al. [10] defined UHPC as an advanced cementitious composite consisting of a dense high strength matrix and fibers (a high quantity of cement, fine aggregate, silica fume, low quantity of water, high range water reducing agent and incorporates large amounts of fibers). They provided experimental test results for flexural behavior of UHPC beams with compressive strength equal to $190 \mathrm{MPa}$. The tested parameter was the amount of rebar with rebar ratios from 0.006 to 0.0196 . UHPC was effective at controlling cracks and showed a ductile behavior with a ductility index ranging between 1.60 and 3.75. The flexure capacity was increased from 0.006 to 0.0196 by $56 \%$.

M. Kamal et al. [11] examined the behavior of UHPC beams with compressive strength equal to $135 \mathrm{MPa}$. The tested parameters were the amount of rebar (0.012-0.017) in addition to the existence or absence of the web reinforcement. In beams without web reinforcement, 
the shear strength and ultimate loads were increased. The flexure capacity was increased from 0.012 to 0.017 by $40 \%$. The number of cracks was increased, and the width of cracks was decreased at failure load, this led to increasing the stiffness. The ductility index ranging between 1.55 and 1.75 .

Venkatesh Kodur et al. [12] analyzed failure characteristics of UHPC beams under flexural and shear loading. The flexure capacity was increased from 0.09 to 0.012 rebar ratio by $30 \%$. The beams without shear reinforcement didn't show any reduction in either ductility or moment capacity of the beams. M. Singh et al. [13] showed the ductility index for simple UHPC beams ranging between 3.65 and 8.44.

M. Saadeghvaziri [14] investigated the effect of eccentricity in RC members. As increasing the axial load (decreasing the eccentricity) led to increase in flexure capacity and stiffness of the members. UHPC increased the stiffness of the concrete beams and deformations were reduced [15]. The cover could affect the cracking pattern and consequently the capacity of concrete beams [16]. UHPC members showed high impact resistance [17].

Most studies on UHPC have concentrated on special concrete materials with characteristics that differ from those of normal strength concrete at the material level. However, few researches are available on the uniaxial flexural capacity, ductility, reinforcement ratio and serviceability of UHPC beams at the structural level. The prime objective of our research is to investigate theoretically the basic uniaxial flexural behavior of UHPC simple beams with parametrs (reinforcement ratio, concrete compressive strength, eccentricity ratio and concrete cover). The study focuses on cracking and failure pattern, serviceability, ductility and flexural capacity. A finite element analyses were conducted to simulate the uniaxial flexural behavior of UHPC simple beams.

\section{FINITE ELEMENT MODELING}

The Finite Element Method (FEM) involves using numerical techniques to find approximate solutions to partial differential equations. The approach involves dividing a body into finite elements connected to one another by nodes to obtain approximate solutions to the field problem in question.

\subsection{Materials and Elements Properties}

The coefficients of UHPC material were validated with experimental tests for In Hwan et al. [10] to obtain accurate coefficients for UHPC to use in FEM. The results agreed well with tests results. The elements used to simulate the materials are Soild65 for UHPC, Link180 for compression, tension and stirrups steel and Solid185 for support and loading plates [18]. Poisson's ratio was assumed to be constant for all specimens and equal to 0.30 . Properties of UHPC for all specimens expect concrete compressive strength specimens were, modulus of elasticity equal to $46.4 \mathrm{GPa}$, the compressive strength was $190 \mathrm{MPa}$ and tensile strength was $12 \mathrm{MPa}$.

The multilinear isotropic stress strain curve used to simulate UHPC is shown in Fig. 1. For concrete compressive strength parameter specimens, we used nonlinear equation [19] to obtain stress-strain relationship from the same approach for different $F_{c u}$ as shown in Eq. 1 . Applying the data gathered from previous researches [10] [20] [21] [22] in Eq. 1, 2, 3 and 4. The properties of compressive strength specimens as shown in Fig. 2 and Table 1. The Failure Criteria of UHPC is shown in Table 2.

$$
\frac{f}{f_{\mathrm{o}}}=\frac{R\left(\frac{\epsilon}{\epsilon_{\mathrm{o}}}\right)}{1+(R-1)\left(\frac{\epsilon}{\epsilon_{\mathrm{o}}}\right)^{B}}
$$


Where, $\beta=\mathrm{R} /(\mathrm{R}-1), \mathrm{R}=$ material parameter depending on the shape of stress strain curve $=E_{\mathrm{c}} / \mathrm{E}_{\mathrm{o}}, \mathrm{E}_{\mathrm{c}}=$ modulus of elasticity of concrete, $\mathrm{E}_{\mathrm{o}}=\max$. Stress $\mathrm{f}_{\mathrm{o}} /$ strain at max. Stress $\mathrm{C}_{\mathrm{o}}$.

$$
\begin{aligned}
& \epsilon_{\mathrm{o}}=0.000875\left(\mathrm{f}_{\mathrm{o}}\right)^{0.3} \\
& \mathrm{E}_{\mathrm{c}}=4400\left(\mathrm{~F}_{\mathrm{cu}}\right)^{0.45} \\
& \mathrm{~F}_{\mathrm{t}}=0.60\left(\mathrm{~F}_{\mathrm{cu}}\right)^{0.497}
\end{aligned}
$$

For steel reinforcement the Yield Stress $\left(\mathrm{F}_{\mathrm{y}}\right)$ was 240 for stirrups and $600 \mathrm{MPa}$ for tension and compression steel, as well as the Hardening Modulus (tangent modulus of the plastic region) of steel was $2100 \mathrm{MPa}$ for the bilinear model. Elastic Modulus (EX) was $200 \mathrm{GPa}$ and Poisson's Ratio was 0.3. For loading and supporting steel plates were modeled as an elastic linear isotropic material with Elastic Modulus (EX) equal $2 \times 10^{7}$ and Poisson's Ratio equal 0.30 .

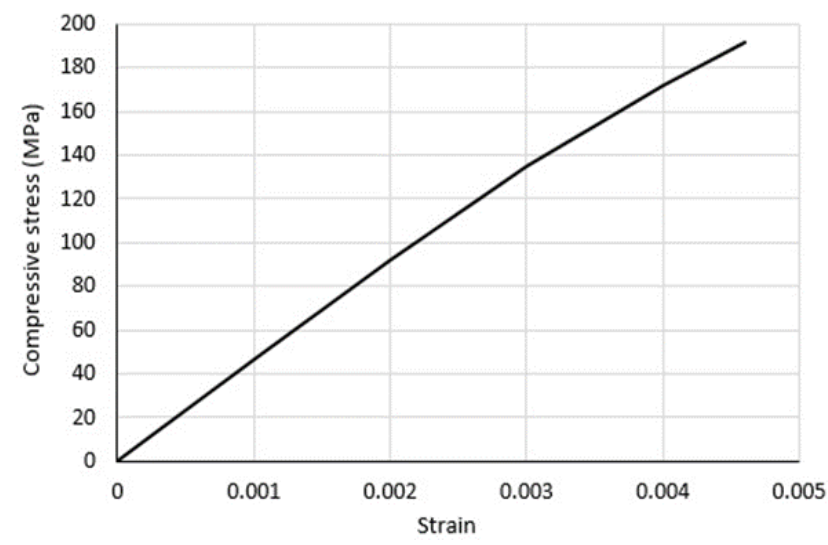

Figure 1 Multi-linear Isotropic Stress-Strain Curve for UHPC

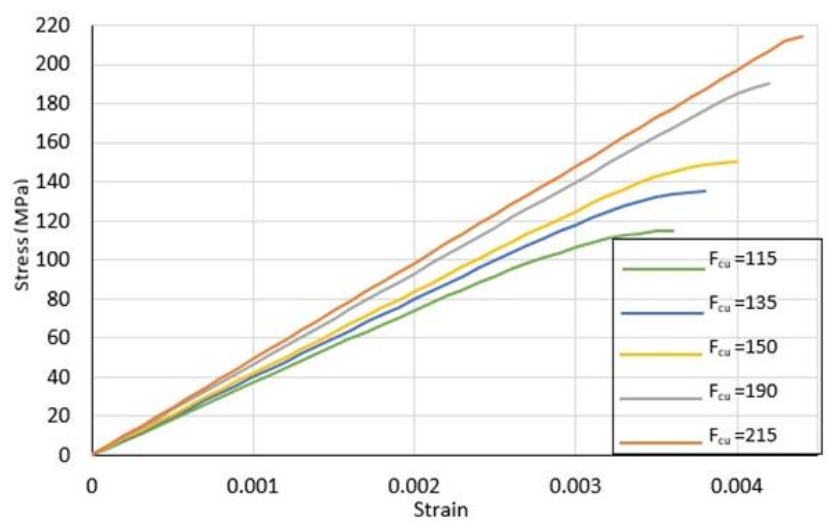

Figure 2 Stress-Strain Curve for Compressive Strength Specimens

Table 1 Material Properties from Nonlinear Equations

\begin{tabular}{|c|c|c|c|c|c|}
\hline $\mathbf{F}_{\mathbf{c u}}(\mathbf{M P a})$ & $\mathbf{F}_{\mathbf{t}}(\mathbf{M P a})$ & $\mathbf{E}_{\mathbf{c}}(\mathbf{G P a})$ & $\mathbf{C}_{\mathbf{o}}$ & $\mathbf{R}$ & $\boldsymbol{\beta}$ \\
\hline 115 & 6.25 & 37.2 & 0.0036 & 1.175 & 6.72 \\
\hline 135 & 6.77 & 40 & 0.0038 & 1.129 & 8.75 \\
\hline 150 & 7.14 & 41.9 & 0.0039 & 1.099 & 10.19 \\
\hline 190 & 8.027 & 46.6 & 0.0042 & 1.036 & 28.62 \\
\hline 215 & 8.536 & 49.3 & 0.0044 & 1.005 & 209.33 \\
\hline
\end{tabular}


Table 2 Failure Criteria Constants of UHPC

\begin{tabular}{|l|l|}
\hline Open Shear Transfer Coef. & 0.40 \\
\hline Closed Shear Transfer Coef. & 0.95 \\
\hline Uniaxial Cracking Stress & Tensile strength \\
\hline Uniaxial Crushing Stress & Compressive strength \\
\hline Tensile Crack Factor & 0.80 \\
\hline
\end{tabular}

For failure criteria constants, the shear transfer coefficient represents a shear strength reduction factor for subsequent loads that induce sliding (shear) across the crack face. Typical shear transfer coefficients range from 0.0 to 1.0. Value of 0.0 represents a smooth crack (complete loss of shear transfer) and 1.0 represents a rough crack (no loss of shear transfer) [18]. The tensile crack factor represents the multiplier for amount of tensile stress relaxation after cracking due to reduction in stiffness and it ranges from 0.0 to 1.0. In this study, many analysis attempts had been done to determine the appropriate values for shear transfer coefficients and tensile crack factor based on comparison of FE load-displacement values with experimental results.

\subsection{Beam Specimen Details and Methodology}

The geometrical properties of all tested beams remained constant with $\mathrm{R}$-sec beam with dimensions $250 \mathrm{~mm}$ × $500 \mathrm{~mm}$ x $5000 \mathrm{~mm}$. The beams were simply supported under fourpoint loading as shown in Fig. 3. The steel loading and supporting plates were $25 \mathrm{~mm} \times 100$ $\mathrm{mm} \times 250 \mathrm{~mm}$. In addition to steel plate with 25x250x500 at the end of the beams for applying the axial force for eccentricity parameters beams. The real constant was the crosssectional area for steel reinforcement. The details of beams and the arrangement of steel reinforcement were shown in Table 3 and Fig. 4. Volumes created in ANSYS was shown in Fig. 5.

The overall size of the mesh used is $30 \mathrm{~mm}^{2}$. Number of elements and nodes for the models were different due to cut the volume of the model in the places of steel to draw it exactly through the nodes and meshed with the same element size. The beams were modeled as a half of each full beam by taking advantage of the symmetry of the beams about one plane. Nodes defining a vertical plane through the beam mid-section define a plane of symmetry. To model the symmetry the nodes on this plane must be constrained in the perpendicular direction. Therefore, these nodes have a degree of freedom constraint UX $=0$.

The support was modeled as a roller. A line of nodes on the middle of the support plate were given constraint in the UY, and UZ directions, applied as constant values of 0 . The flexure force is applied at the steel plate and applied across all the nodes on the top face of plate. The load was applied at equal increments of $2 \mathrm{KN}$ for the half beam models. For the eccentricity parameter beams, the axial loads were applied as a function of vertical loads for different eccentricity ratios according to the follow formulas:

Moment $(\mathrm{M})=\mathrm{PL} / 4 \quad$ where $\mathrm{P}$ is the half of flexure load

Eccentricity $(\mathrm{e})=\mathrm{M} / \mathrm{N} \quad$ where $\mathrm{N}$ is the axial force

Setting solution parameters involves defining the analysis type (nonlinear static) and common analysis options for the analysis. As well as specifying load step options for it. The maximum and minimum load step sizes are $2 \mathrm{KN}$ and $1 \mathrm{KN}$. The maximum number of iteration used is 25 . The convergence criteria used is displacement criteria with tolerance equal to 0.01 . 
Theoretical Study of Uniaxial Flexural Behavior of Ultra High-Performance Reinforced Concrete Beams

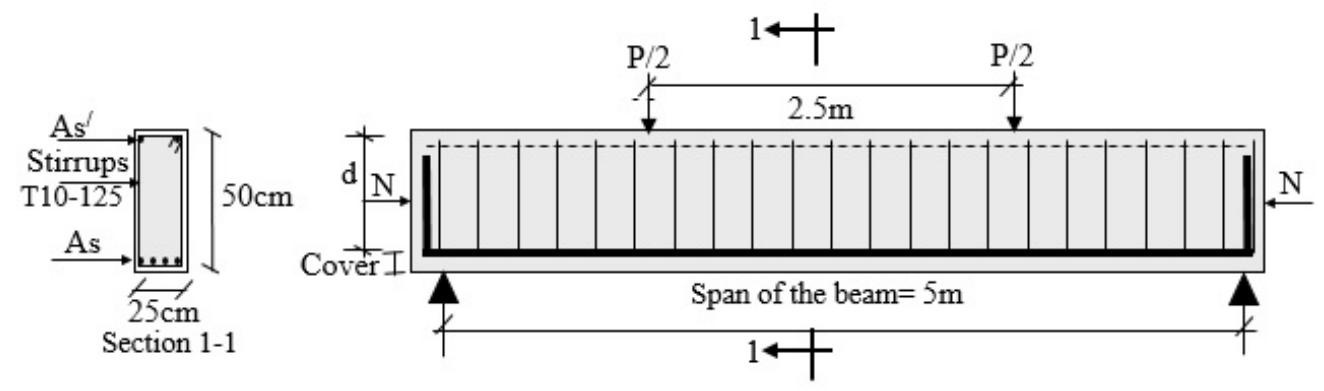

Figure 3 Details of the Tested Beams

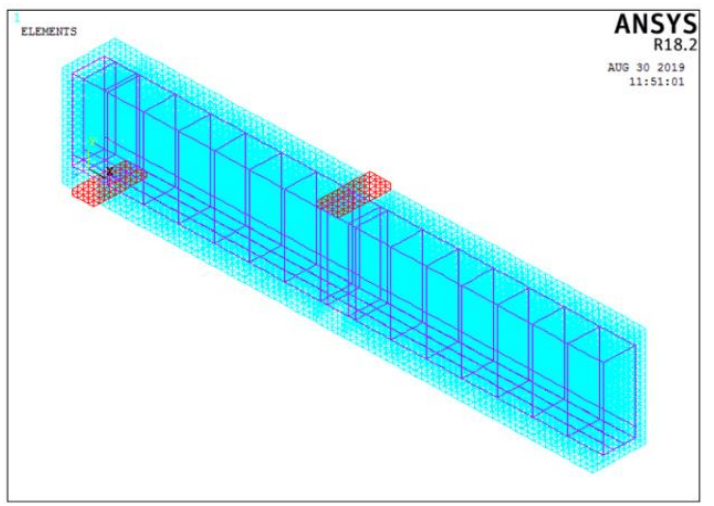

Figure 4 Arrangement of RFT for Half of Beam

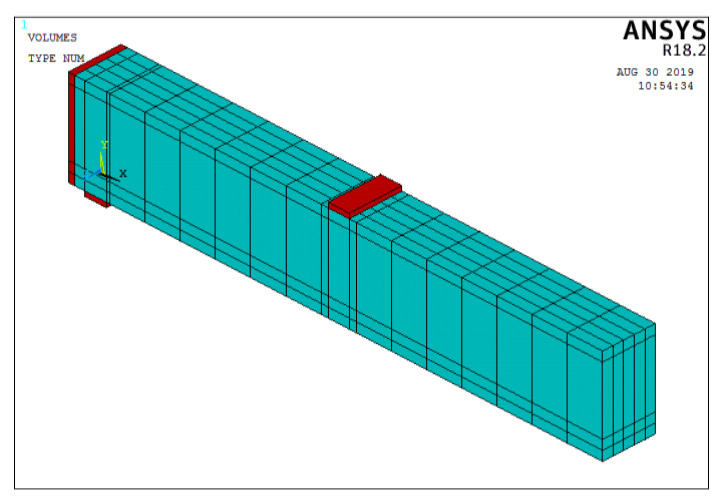

Figure 5 Volume Created for Half of Beam

Table 3 Details of the Beams

- Beam $\left(\mathrm{B}_{\mathrm{o}}\right)$ is the control beam

\begin{tabular}{|c|c|c|c|c|c|c|c|}
\hline Group & Specimen & $\begin{array}{l}\text { Cover } \\
(\mathbf{m m})\end{array}$ & $\mathrm{e} / \mathrm{t}$ & $\begin{array}{c}\text { Concrete } \\
\text { Strength } \\
\text { (MPa) }\end{array}$ & As/Ac & RFT & $\mathbf{A s}$ \\
\hline \multirow{6}{*}{1} & $\mathrm{~B}_{1}$ & \multirow{6}{*}{50} & $\infty$ & 190 & $0.3 \%$ & 4D12 & 2D12 \\
\hline & $\mathrm{B}_{2}$ & & $\infty$ & 190 & $0.6 \%$ & 4D16 & 2D16 \\
\hline & $\mathrm{B}_{3}$ & & $\infty$ & 190 & $0.8 \%$ & 4D18 & 2D18 \\
\hline & $\mathrm{B}_{4}$ & & $\infty$ & 190 & $1.2 \%$ & 6D18 (4+2) & 2D18 \\
\hline & $\mathrm{B}_{\mathrm{o}}$ & & $\infty$ & 190 & $1.6 \%$ & 8D18 (4+4) & 2D18 \\
\hline & $\mathrm{B}_{5}$ & & $\infty$ & 190 & $3 \%$ & $\begin{array}{c}10 \mathrm{D} 22 \\
(4+4+2)\end{array}$ & $2 \mathrm{D} 22$ \\
\hline \multirow{5}{*}{2} & $\mathrm{~B}_{6}$ & \multirow{5}{*}{50} & $\infty$ & 115 & \multirow{5}{*}{$1.6 \%$} & \multirow{5}{*}{$\begin{array}{l}8 \mathrm{D} 18 \\
(4+4)\end{array}$} & \multirow{5}{*}{ 2D18 } \\
\hline & $\mathrm{B}_{7}$ & & $\infty$ & 135 & & & \\
\hline & $\mathrm{B}_{8}$ & & $\infty$ & 150 & & & \\
\hline & $\mathrm{B}_{9}$ & & $\infty$ & 190 & & & \\
\hline & $\mathrm{B}_{10}$ & & $\infty$ & 215 & & & \\
\hline \multirow{4}{*}{3} & $\mathrm{~B}_{11}$ & \multirow{4}{*}{50} & 0.5 & 190 & \multirow{4}{*}{$1.6 \%$} & \multirow{4}{*}{$\begin{array}{l}8 \mathrm{D} 18 \\
(4+4)\end{array}$} & \multirow{4}{*}{ 2D18 } \\
\hline & $\mathrm{B}_{12}$ & & 1 & 190 & & & \\
\hline & $\mathrm{B}_{13}$ & & 1.5 & 190 & & & \\
\hline & $\mathrm{B}_{\mathrm{o}}$ & & $\infty$ & 190 & & & \\
\hline \multirow{5}{*}{4} & $\mathrm{~B}_{14}$ & 30 & $\infty$ & 190 & \multirow{5}{*}{$1.6 \%$} & \multirow{5}{*}{$\begin{array}{l}8 \mathrm{D} 18 \\
(4+4)\end{array}$} & \multirow{5}{*}{ 2D18 } \\
\hline & $\mathrm{B}_{15}$ & 40 & $\infty$ & 190 & & & \\
\hline & $\mathrm{B}_{\mathrm{o}}$ & 50 & $\infty$ & 190 & & & \\
\hline & $\mathrm{B}_{16}$ & 60 & $\infty$ & 190 & & & \\
\hline & $\mathrm{B}_{17}$ & 70 & $\infty$ & 190 & & & \\
\hline
\end{tabular}




\section{RESULTS OF THE FE. MODELS}

\subsection{Load versus Deflection Response}

The load-midspan deflection curves for all test specimens are shown from Fig. 6 to Fig. 9. In addition to the loads and deflections at the first cracking state, steel rebar yielding state, and failure state are summarized in Table 4. Failure load is defined when the instant stiffness become less than $10 \%$ stiffness before cracking. After the cracking load the stiffness was decreased with high value in the next sub-step before the reinforcement counteracts this on the next sub-step.

The first cracking load was $228 \mathrm{KN}$ for $\mathrm{B}_{1}$ with $0.30 \%$ reinforcement ratio. It was increased slightly with increasing the reinforcement ratio to $0.60,0.80,1.2,1.6$ and $3 \%$ for beam $\mathrm{B}_{2}, \mathrm{~B}_{3}, \mathrm{~B}_{4}, \mathrm{~B}_{0}$ and $\mathrm{B}_{5}$ by $3.5,7,8.8,12.3$ and $22.8 \%$ respectively. The stiffness at first cracking state was 81.55 for beam $\mathrm{B}_{1}$. It was increased slightly by $3.2,5.1,6.8,8.4$ and 15.2 $\%$ for $\mathrm{B}_{2}, \mathrm{~B}_{3}, \mathrm{~B}_{4}, \mathrm{~B}_{0}$ and $\mathrm{B}_{5}$ respectively compared to stiffness of $\mathrm{B}_{1}$. The cracking load was calculated from the capacity of the section without reinforcement and mentioned on Fig. 6. The load was increased until the steel yielded. The yield load for beam $B_{1}$ was $232 \mathrm{KN}$. It was increased significantly by $59,91.4,163.8,226.7$ and $437.9 \%$ for $\mathrm{B}_{2}, \mathrm{~B}_{3}, \mathrm{~B}_{4}, \mathrm{~B}_{0}$ and $\mathrm{B}_{5}$ respectively.

The stiffness at yielding was 13.07 for beam $\mathrm{B}_{1}$. It was increased significantly by 55.10 , $54.48,105.74,129.92$ and $222 \%$ for $\mathrm{B}_{2}, \mathrm{~B}_{3}, \mathrm{~B}_{4}, \mathrm{~B}_{0}$ and $\mathrm{B}_{5}$ respectively compared to stiffness of $B_{1}$. The load was increased until the failure load. The failure load was $232 \mathrm{KN}$ for beam $\mathrm{B}_{1}$. The flexure capacity (failure load) was increased significantly by 63, 91, 159, 261 and $541 \%$ for $\mathrm{B}_{2}, \mathrm{~B}_{3}, \mathrm{~B}_{4}, \mathrm{~B}_{\mathrm{o}}$ and $\mathrm{B}_{5}$ respectively. The stiffness at failure state was 13.06 for beam $\mathrm{B}_{1}$. It was increased significantly by $52.1,54.6,95.6,113.7$ and $173.1 \%$ for $\mathrm{B}_{2}, \mathrm{~B}_{3}, \mathrm{~B}_{4}, \mathrm{~B}_{0}$ and $\mathrm{B}_{5}$ respectively compared to stiffness of $\mathrm{B}_{1}$.

The first cracking load was $136 \mathrm{KN}$ for $\mathrm{B}_{6}$ with $115 \mathrm{MPa}$ compressive strength. It was increased with increasing the compressive strength to $135,150,190$ and $215 \mathrm{MPa}$ for $\mathrm{B}_{7}, \mathrm{~B}_{8}$, $\mathrm{B}_{9}$ and $\mathrm{B}_{10}$ respectively by $8.82,11.77,26.47$ and $32.35 \%$. The stiffness at first cracking state was 72.88 for $\mathrm{B}_{6}$. It was increased by $6.49,11,21.85$ and $28.10 \%$ for $\mathrm{B}_{7}, \mathrm{~B}_{8}, \mathrm{~B}_{9}$ and $\mathrm{B}_{10}$ respectively compared to stiffness of $\mathrm{B}_{6}$. The load was increased until the steel yielded. The yield load was $738 \mathrm{KN}$ for beam $\mathrm{B}_{6}$. It was increased slightly by $0.54,2.98,1.90$ and $2.44 \%$ for $\mathrm{B}_{7}, \mathrm{~B}_{8}, \mathrm{~B}_{9}$ and $\mathrm{B}_{10}$ respectively.

The stiffness at yielding was 27.2 for $\mathrm{B}_{6}$. It was increased slightly by $0.30,0.34,3.1$ and 5 $\%$ for $\mathrm{B}_{7}, \mathrm{~B}_{8}, \mathrm{~B}_{9}$ and $\mathrm{B}_{10}$ respectively compared to stiffness of $\mathrm{B}_{6}$. The load was increased until the failure load. The flexure capacity (failure load) was $826,818,840,816$ and $820 \mathrm{KN}$ for $\mathrm{B}_{6}, \mathrm{~B}_{7}, \mathrm{~B}_{8}, \mathrm{~B}_{9}$ and $\mathrm{B}_{10}$ respectively. The stiffness at failure state was 25.55 for $\mathrm{B}_{6}$. It was increased slightly by $1.29,2.31,6.50$ and $9.32 \%$ for $\mathrm{B}_{7}, \mathrm{~B}_{8}, \mathrm{~B}_{9}$ and $\mathrm{B}_{10}$ respectively compared to stiffness of $\mathrm{B}_{6}$.

The first cracking load was $408 \mathrm{KN}$ for beam $\mathrm{B}_{11}$ with $\mathrm{e} / \mathrm{t}=0.50$. It was decreased with increasing the e / $\mathrm{t}$ ratio (decrease in the compressive axial force) to $1,1.5$ and $\infty$ for beam $\mathrm{B}_{12}, \mathrm{~B}_{13}$ and $\mathrm{B}_{\mathrm{o}}$ respectively by $23.53,28.43$ and $37.25 \%$. The stiffness at first cracking state was 86.44 for $B_{11}$. It wasn't changed approximately for other beams. The load was increased until the steel yielded for beam $\mathrm{B}_{12}, \mathrm{~B}_{13}$ and $\mathrm{B}_{0}$. The steel of $\mathrm{B}_{11}$ didn't reach the yield state until failure. The yield load for beam $B_{12}$ was $1198 \mathrm{KN}$. It was decreased by 15.69 and 36.73 $\%$ for $\mathrm{B}_{13}$ and $\mathrm{B}_{0}$ respectively.

The stiffness at yielding was 39.9 for $\mathrm{B}_{12}$. It was decreased by 9.77 and $24.69 \%$ for $\mathrm{B}_{13}$ and $\mathrm{B}_{\mathrm{o}}$ compared to stiffness of $\mathrm{B}_{12}$. The load was increased until the failure load. The failure load was $1666 \mathrm{KN}$ for beam $\mathrm{B}_{11}$. The flexure capacity (failure load) was decreased by 12 , 30.5 and $49.7 \%$ for $\mathrm{B}_{12}, \mathrm{~B}_{13}$ and $\mathrm{B}_{\mathrm{o}}$ respectively. The stiffness at failure state was 55.63 for 
$\mathrm{B}_{11}$. It was decreased by $40.6,42.7$ and $49.8 \%$ for $\mathrm{B}_{12}, \mathrm{~B}_{13}$ and $\mathrm{B}_{0}$ respectively compared to stiffness of $B_{11}$.

The first cracking load was $264 \mathrm{KN}$ for beam $\mathrm{B}_{14}$ with cover equal to $30 \mathrm{~mm}$. It was decreased slightly with increasing the cover to $40,50,60$ and $70 \mathrm{~mm}$ for beam $\mathrm{B}_{15}, \mathrm{~B}_{0}, \mathrm{~B}_{16}$ and $\mathrm{B}_{17}$ respectively by $1.51,3.03,4.55$, and $6.06 \%$. The stiffness at first cracking state was 91.1 for $\mathrm{B}_{14}$. It was decreased slightly by $1.55,2.96,4.25$ and $5.38 \%$ for $\mathrm{B}_{15}, \mathrm{~B}_{0}, \mathrm{~B}_{16}$ and $\mathrm{B}_{17}$ respectively compared to stiffness of $\mathrm{B}_{14}$. The load was increased until the steel yielded. The yield load for beam $\mathrm{B}_{14}$ was $870 \mathrm{KN}$. It was decreased by $8.28,12.87,18.39$ and $22.76 \%$ for $\mathrm{B}_{15}, \mathrm{~B}_{\mathrm{o}}, \mathrm{B}_{16}$ and $\mathrm{B}_{17}$ respectively.

The stiffness at yielding was 34.61 for $\mathrm{B}_{14}$. It was decreased by $7.17,13.17,18.29$ and $26.73 \%$ for $\mathrm{B}_{15}, \mathrm{~B}_{0}, \mathrm{~B}_{16}$ and $\mathrm{B}_{17}$ compared to stiffness of $\mathrm{B}_{14}$. The load was increased until the failure load. The failure load was $918 \mathrm{KN}$ for beam $\mathrm{B}_{14}$. The flexure capacity (failure load) was decreased by $4.3,8.7,13.5$ and $17.2 \%$ for $\mathrm{B}_{15}, \mathrm{~B}_{0}, \mathrm{~B}_{16}$ and $\mathrm{B}_{17}$ respectively. The stiffness at failure state was 33.11 for $\mathrm{B}_{14}$. It was decreased by $9.4,15.7,19.8$ and $30.6 \%$ for $\mathrm{B}_{15}, \mathrm{~B}_{\mathrm{o}}$, $\mathrm{B}_{16}$ and $\mathrm{B}_{17}$ respectively compared to stiffness of $\mathrm{B}_{14}$.

Table 4 Loads and Deflections for all Loading States

\begin{tabular}{|c|c|c|c|c|c|c|c|c|c|}
\hline \multirow[t]{2}{*}{ Beam } & \multicolumn{2}{|c|}{ First cracking } & \multicolumn{2}{|c|}{ Yielding state } & \multicolumn{3}{|c|}{ Failure state } & \multirow{2}{*}{$\begin{array}{c}\Delta \text { at } \\
60 \% \mathbf{P}_{\mathrm{f}} \\
\Delta_{60 \% \mathrm{Pf}} \\
(\mathrm{mm})\end{array}$} & \multirow{2}{*}{$\begin{array}{c}\begin{array}{c}\text { Ductility } \\
\text { index }\end{array} \\
\mu_{\mathrm{f}}=\Delta_{\mathrm{f}} / \Delta_{\mathrm{y}}\end{array}$} \\
\hline & $\begin{array}{c}\mathbf{P}_{\mathrm{cr}} \\
(\mathbf{K N})\end{array}$ & $\begin{array}{c}\Delta_{\text {cr }} \\
(\mathbf{m m})\end{array}$ & $\begin{array}{c}\mathbf{P}_{\mathbf{y}} \\
(\mathbf{K N})\end{array}$ & $\begin{array}{c}\Delta_{y} \\
(\mathbf{m m})\end{array}$ & $\begin{array}{c}\mathbf{P}_{\mathbf{f}} \\
(\mathbf{K N})\end{array}$ & $\begin{array}{c}\Delta_{\mathbf{f}} \\
(\mathbf{m m})\end{array}$ & $\begin{array}{c}\mathbf{K} \\
(\mathbf{K N} / \mathbf{m m})\end{array}$ & & \\
\hline $\mathrm{B}_{1}$ & 228 & 2.796 & 232 & 17.76 & 232 & 17.76 & 13.06 & 1.70 & 1 \\
\hline $\mathrm{B}_{2}$ & 236 & 2.804 & 369 & 18.20 & 377 & 18.97 & 19.87 & 2.68 & 1.04 \\
\hline $\mathrm{B}_{3}$ & 244 & 2.846 & 444 & 21.99 & 444 & 21.99 & 20.19 & 11.52 & 1 \\
\hline $\mathrm{B}_{4}$ & 248 & 2.848 & 612 & 22.76 & 660 & 25.83 & 25.55 & 13.51 & 1.13 \\
\hline $\mathrm{B}_{\mathrm{o}}$ & 256 & 2.896 & 758 & 25.23 & 838 & 30.02 & 27.91 & 16.05 & 1.19 \\
\hline $\mathrm{B}_{5}$ & 280 & 2.98 & 1248 & 29.66 & 1488 & 41.71 & 35.67 & 20.85 & 1.40 \\
\hline $\mathrm{B}_{6}$ & 136 & 1.866 & 738 & 27.14 & 826 & 32.33 & 25.55 & 17.77 & 1.191 \\
\hline $\mathrm{B}_{7}$ & 148 & 1.907 & 742 & 27.06 & 818 & 31.61 & 25.88 & 17.46 & 1.168 \\
\hline $\mathrm{B}_{8}$ & 152 & 1.879 & 760 & 27.04 & 840 & 32.13 & 26.14 & 17.00 & 1.188 \\
\hline $\mathrm{B}_{9}$ & 172 & 1.937 & 752 & 26.30 & 816 & 29.99 & 27.21 & 16.51 & 1.140 \\
\hline $\mathrm{B}_{10}$ & 180 & 1.928 & 756 & 25.79 & 820 & 29.36 & 27.93 & 16.19 & 1.138 \\
\hline $\mathrm{B}_{11}$ & 408 & 4.72 & - & - & 1666 & 29.95 & 55.63 & 17.02 & - \\
\hline $\mathrm{B}_{12}$ & 312 & 3.57 & 1198 & 30.02 & 1466 & 44.36 & 33.05 & 21.07 & 1.48 \\
\hline$B_{13}$ & 292 & 3.33 & 1010 & 28.05 & 1158 & 36.32 & 31.88 & 18.47 & 1.29 \\
\hline $\mathrm{B}_{\mathrm{o}}$ & 256 & 2.896 & 758 & 25.23 & 838 & 30.02 & 27.91 & 16.05 & 1.19 \\
\hline $\mathrm{B}_{14}$ & 264 & 2.898 & 870 & 25.14 & 918 & 27.72 & 33.11 & 15.15 & 1.103 \\
\hline $\mathrm{B}_{15}$ & 260 & 2.899 & 798 & 24.84 & 878 & 29.27 & 30.00 & 15.74 & 1.178 \\
\hline $\mathrm{B}_{\mathrm{o}}$ & 256 & 2.896 & 758 & 25.23 & 838 & 30.02 & 27.91 & 16.05 & 1.190 \\
\hline $\mathrm{B}_{16}$ & 252 & 2.889 & 710 & 25.11 & 794 & 29.92 & 26.54 & 15.98 & 1.192 \\
\hline $\mathrm{B}_{17}$ & 248 & 2.877 & 672 & 26.50 & 760 & 33.08 & 22.98 & 17.22 & 1.248 \\
\hline
\end{tabular}


Wael M. Montaser, Ayman Hussein Hosny Khalil and Ahmed A. Abdel-Bary

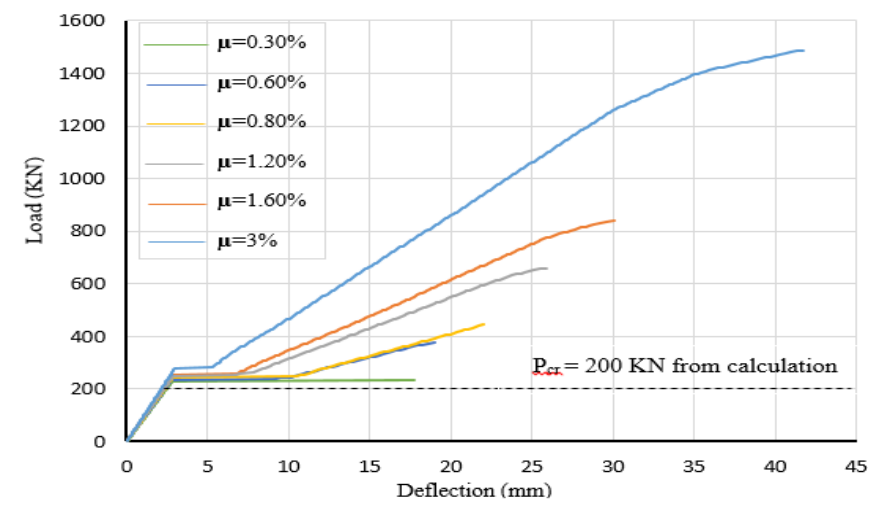

Figure 6 Load-Midspan Deflection Curve for $\mathrm{B}_{1}, \mathrm{~B}_{2}, \mathrm{~B}_{3}, \mathrm{~B}_{4}, \mathrm{~B}_{\mathrm{o}}$ and $\mathrm{B}_{5}$

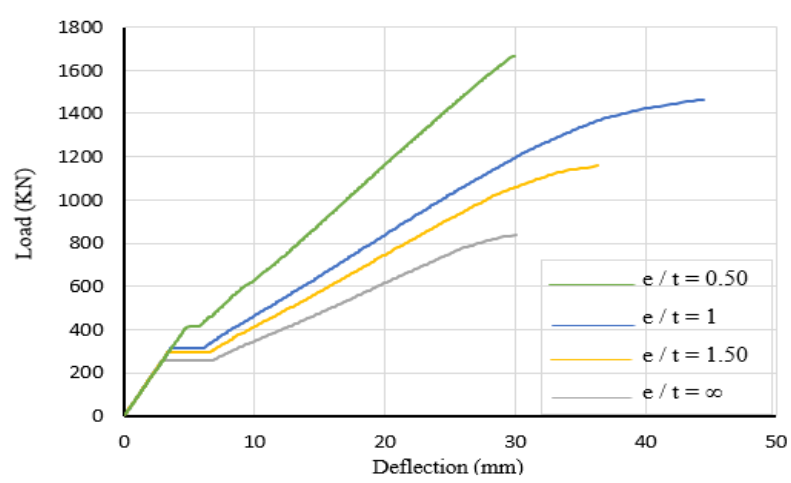

Figure 7 Load-Midspan Deflection Curve for $\mathrm{B}_{11}, \mathrm{~B}_{12}, \mathrm{~B}_{13}$ and $\mathrm{B}_{\mathrm{o}}$

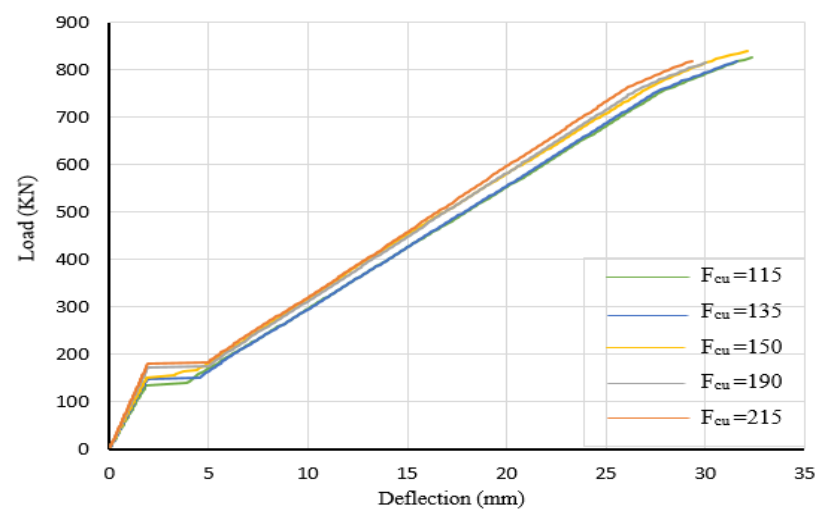

Figure 8 Load-Midspan Deflection Curve for $\mathrm{B}_{6}, \mathrm{~B}_{7}, \mathrm{~B}_{8}, \mathrm{~B}_{9}$ and $\mathrm{B}_{10}$

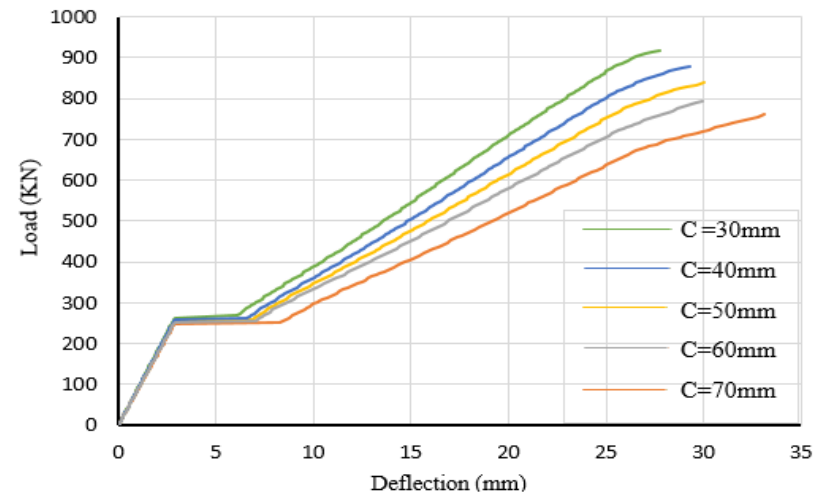

Figure 9 Load-Midspan Deflection Curve for $\mathrm{B}_{14}, \mathrm{~B}_{15}, \mathrm{~B}_{0}, \mathrm{~B}_{16}$ and $\mathrm{B}_{17}$ 


\subsection{Crack and Failure Patterns}

The cracks were observed at first crack load with micro-cracks occurred at the bottom face of the beam between the loading points where the beam was subjected to pure bending. Vertical flexural cracks were formed perpendicular to the maximum principle stress direction toward the top face. When applied loads increased, vertical flexural cracks were spread horizontally from the mid-span to the support. For $\mathrm{B}_{1}, \mathrm{~B}_{2}, \mathrm{~B}_{3}, \mathrm{~B}_{4}, \mathrm{~B}_{\mathrm{o}}$ and $\mathrm{B}_{5}$, the propagation of vertical cracks was decreased by increasing the reinforcement ratio at the pure bending zone. At the shear zone, the propagation of vertical cracks was increased by increasing the reinforcement ratio. The propagation of horizontal cracks was increased by increasing the reinforcement ratio.

For $\mathrm{B}_{6}, \mathrm{~B}_{7}, \mathrm{~B}_{8}, \mathrm{~B}_{9}$ and $\mathrm{B}_{10}$, the propagation of vertical cracks showed almost the same behavior by increasing the compressive strength at the pure bending zone. The propagation of vertical and horizontal cracks was decreased slightly at the shear zone by increasing the compressive strength. For $\mathrm{B}_{11}, \mathrm{~B}_{12}$ and $\mathrm{B}_{13}$, the propagation of vertical and horizontal cracks was showed almost the same behavior for the eccentricity ratio $1,1.5$ and $\infty$. $\mathrm{B}_{11}$ showed less propagation of cracks than other beams significantly. The compressive cracks were showed and significantly increased by decreasing the eccentricity ratio. $\mathrm{B}_{11}$ showed high propagation of cracks at compression zone.

For $\mathrm{B}_{14}, \mathrm{~B}_{15}, \mathrm{~B}_{16}$ and $\mathrm{B}_{17}$, the propagation of vertical cracks was increased slightly by increasing the concrete cover at pure bending zone. The propagation of vertical and horizontal cracks showed almost the same behavior by increasing the concrete cover at the shear zone. The failure mode for all beams were flexure failure before UHPC reach the compressive strength expect $\mathrm{B}_{11}$ showed compressive failure due to reach the maximum compressive strength. Fig. 10 to Fig. 17 show propagation of cracks for some beams (half beam) at failure.

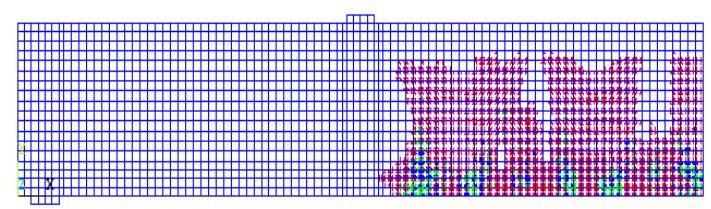

Figure 10 The propagation of cracks at Failure for half beam $B_{1}$

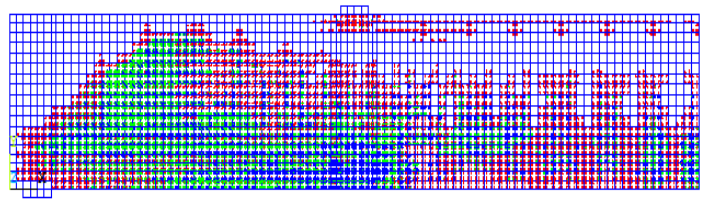

Figure 11 The propagation of cracks at Failure for half beam $B_{5}$

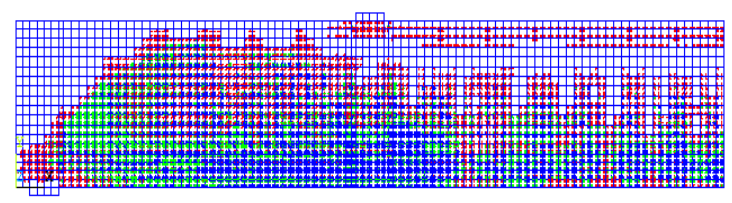

Figure 12 The propagation of cracks at Failure for half beam $\mathrm{B}_{6}$

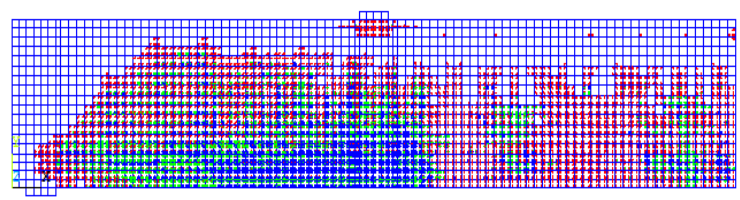

Figure 13 The propagation of cracks at Failure for half beam $B_{10}$ 


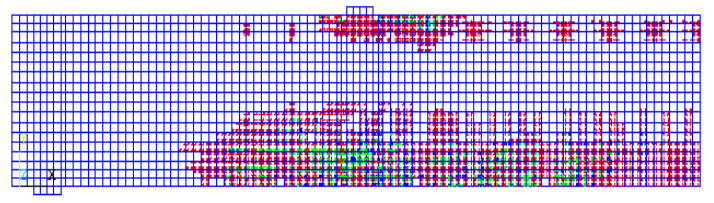

Figure 14 The propagation of cracks at Failure for half beam $B_{11}$

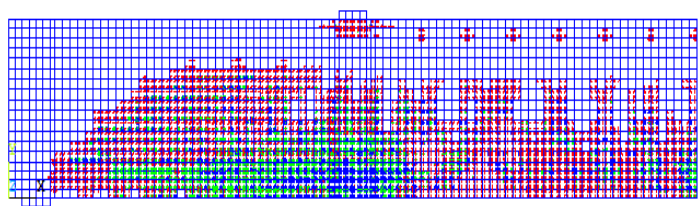

Figure 15 The propagation of cracks at Failure for half beam $B_{13}$

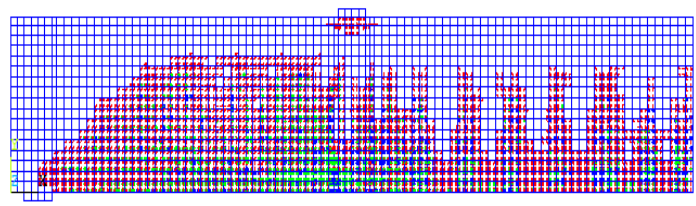

Figure 16 The propagation of cracks at Failure for half beam B 14

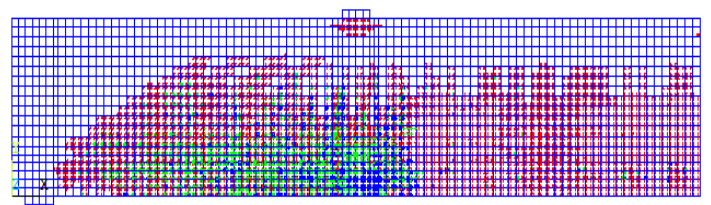

Figure 17 The propagation of cracks at Failure for half beam $\mathrm{B}_{17}$

\subsection{Ductility}

The ductility of a concrete structure can be used as a measure of the resistance of the structural member or structural system to deformation during transition from the elastic zone to the plastic zone until failure. This can also be interpreted as a measure of the energy absorption capacity of the structural member. In general the ductility of a concrete structure can be quantified via the ductility index, which can be expressed in terms of the deflection ductility index as expressed in Eq. (7).

$$
\mu_{\mathrm{f}}=\Delta_{\mathrm{f}} / \Delta_{\mathrm{y}}
$$

Where $\mu$ is the ductility index, $\Delta_{\mathrm{f}}$ is the failure deflection and $\Delta_{\mathrm{y}}$ is the yielding deflection. Table 4 shows the ductility index for beams. The ductility index wasn't affected by changing the reinforcement ratio from 0.3 to $0.8 \%$. After that the ductility index was increased by increasing the reinforcement ratio. It was increased by 13,19 and $40 \%$ for $\mathrm{B}_{4}, \mathrm{~B}_{\mathrm{o}}$ and $\mathrm{B}_{6}$ compared to the ductility index of $\mathrm{B}_{3}$. The compressive strength doesn't affect the ductility of the beams and all beams had the same value of ductility index almost. The ductility index was decreased by increasing the eccentricity ratio from 1 to 1.5 and $\infty$ respectively. The ductility index for $\mathrm{B}_{12}$ was 1.48 . It was decreased by 12.8 and $19.6 \%$ for $\mathrm{B}_{13}$ and $\mathrm{B}_{0}$. The ductility index was increased by increasing the concrete cover. The ductility index for $\mathrm{B}_{14}$ was 1.103 . It was increased by $6.8,7.9,8.1$ and $13.1 \%$ for $\mathrm{B}_{15}, \mathrm{~B}_{\mathrm{o}}, \mathrm{B}_{16}$ and $\mathrm{B}_{17}$ respectively.

\subsection{Load Versus Strain Response}

\subsubsection{Compressive UHPC Strain}

For all specimens, the compressive concrete strain response experienced approximately a linear behavior up to yielding state, similar to deflection response. After the first crack 
substep, high strain hardening occurred due to reduction in stiffness until the reinforcement counteracts this on the next load substep. Strain hardening continued until failure.

The first cracking strain for $\mathrm{B}_{1}, \mathrm{~B}_{2}, \mathrm{~B}_{3}, \mathrm{~B}_{4}, \mathrm{~B}_{0}$ and $\mathrm{B}_{5}$ was the same value equal to $260 \mu \varepsilon$. The maximum midspan strain at failure was 699, 836, 896, 1220, 1420 and $2290 \mu \varepsilon$ for $\mathrm{B}_{1}$, $\mathrm{B}_{2}, \mathrm{~B}_{3}, \mathrm{~B}_{4}, \mathrm{~B}_{0}$ and $\mathrm{B}_{5}$ respectively. The failure strain at was increased by increasing the reinforcement ratio by $19.6,28.2,74.5,103.2$ and $227.6 \%$ for $\mathrm{B}_{2}, \mathrm{~B}_{3}, \mathrm{~B}_{4}, \mathrm{~B}_{0}$ and $\mathrm{B}_{5}$ respectively compared to strain of $\mathrm{B}_{1}$. The first cracking strain for $\mathrm{B}_{6}, \mathrm{~B}_{7}, \mathrm{~B}_{8}, \mathrm{~B}_{9}$ and $\mathrm{B}_{10}$ was $175,178,184,176$ and 180 respectively. So, the strain at first cracking load was approximately the same value for different compressive strength beams. The maximum midspan strain at failure was $1650,1570,1570,1490$ and $1360 \mu \varepsilon$ for $\mathrm{B}_{6}, \mathrm{~B}_{7}, \mathrm{~B}_{8}, \mathrm{~B}_{9}$ and $\mathrm{B}_{10}$ respectively. The failure strain at was decreased by 4.8, 4.8, 9.7 and $17.5 \%$ by increasing the compressive strength for $\mathrm{B}_{7}, \mathrm{~B}_{8}, \mathrm{~B}_{9}$ and $\mathrm{B}_{10}$ respectively compared to $\mathrm{B}_{6}$.

The first cracking strain for $\mathrm{B}_{11}, \mathrm{~B}_{12}, \mathrm{~B}_{13}$ and $\mathrm{B}_{\mathrm{o}}$ was $602,392,343$ and $260 \mu \varepsilon$ respectively. So, the strain was decreased by increasing the eccentricity ratio by 35,43 and 57 $\%$ for $\mathrm{B}_{12}, \mathrm{~B}_{13}$ and $\mathrm{B}_{0}$ respectively compared to strain of $\mathrm{B}_{11}$. The maximum midspan strain at failure was 2990, 2860, 2120 and $1420 \mu \varepsilon$ for $\mathrm{B}_{11}, \mathrm{~B}_{12}, \mathrm{~B}_{13}$ and $\mathrm{B}_{\mathrm{o}}$ respectively. The strain at failure was decreased by increasing the eccentricity ratio by $4.3,29.1$ and $52.5 \%$ for $\mathrm{B}_{12}, \mathrm{~B}_{13}$ and $\mathrm{B}_{\mathrm{o}}$ respectively compared to strain of $\mathrm{B}_{11}$.

The first cracking strain for $\mathrm{B}_{14}, \mathrm{~B}_{15}, \mathrm{~B}_{0}, \mathrm{~B}_{16}$ and $\mathrm{B}_{17}$ was the same value equal to $260 \mu \varepsilon$. The maximum midspan strain at failure was $1450,1440,1420,1490$ and $1530 \mu \varepsilon$ for $\mathrm{B}_{14}, \mathrm{~B}_{15}$, $\mathrm{B}_{0}, \mathrm{~B}_{16}$ and $\mathrm{B}_{17}$ respectively. So, the strain at failure was shown almost the same behavior by increasing the concrete cover. Fig. 18 to Fig. 21 show comparative compressive UHPC strain with loads for all beams.

\subsubsection{Tensile Steel Stress}

The reinforcement for all beams yielded at the same strain with an average equal to $3000 \mu \varepsilon$ expect $\mathrm{B}_{11}$ didn't reach yielding. The maximum midspan strain at failure was 5880, 4990, $3000,6520,5270$ and $8900 \mu \varepsilon$ for $\mathrm{B}_{1}, \mathrm{~B}_{2}, \mathrm{~B}_{3}, \mathrm{~B}_{4}, \mathrm{~B}_{0}$ and $\mathrm{B}_{5}$ respectively. The maximum midspan strain at failure was $4760,3890,6270,3820$ and $3520 \mu \varepsilon$ for $\mathrm{B}_{6}, \mathrm{~B}_{7}, \mathrm{~B}_{8}, \mathrm{~B}_{9}$ and $\mathrm{B}_{10}$ respectively.

The maximum midspan strain prior to failure was $2260,9120,6690$ and $5270 \mu \varepsilon$ for $\mathrm{B}_{11}$, $\mathrm{B}_{12}, \mathrm{~B}_{13}$ and $\mathrm{B}_{\mathrm{o}}$ respectively. The strain at failure was decreased by increasing the eccentricity ratio by 30.26 and $67 \%$ for $\mathrm{B}_{13}$ and $\mathrm{B}_{0}$ compared to $\mathrm{B}_{12}$. The maximum midspan strain prior to failure was $3970,6610,5270,4940$ and $4390 \mu \varepsilon$ for $\mathrm{B}_{14}, \mathrm{~B}_{15}, \mathrm{~B}_{0}, \mathrm{~B}_{16}$ and $\mathrm{B}_{17}$ respectively. The strain at failure was decreased by increasing the concrete cover to 50,60 and $70 \mathrm{~mm}$ by 20,25 and $33.6 \%$ for $\mathrm{B}_{0}, \mathrm{~B}_{16}, \mathrm{~B}_{17}$ compared to strain of $\mathrm{B}_{15}$ with $40 \mathrm{~mm}$ concrete cover. $\mathrm{B}_{14}$ showed the lowest strain with low concrete cover. Fig. 22 to Fig. 25 show comparative tensile steel strain with loads for all beams.

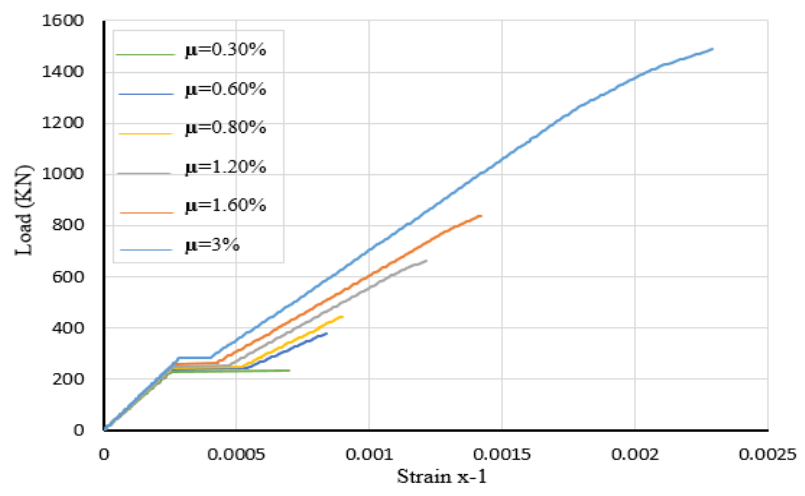

Figure 18 Load-Midspan Compressive UHPC Strain Curve for $\mathrm{B}_{1}, \mathrm{~B}_{2}, \mathrm{~B}_{3}, \mathrm{~B}_{4}, \mathrm{~B}_{\mathrm{o}}$ and $\mathrm{B}_{5}$ 
Wael M. Montaser, Ayman Hussein Hosny Khalil and Ahmed A. Abdel-Bary

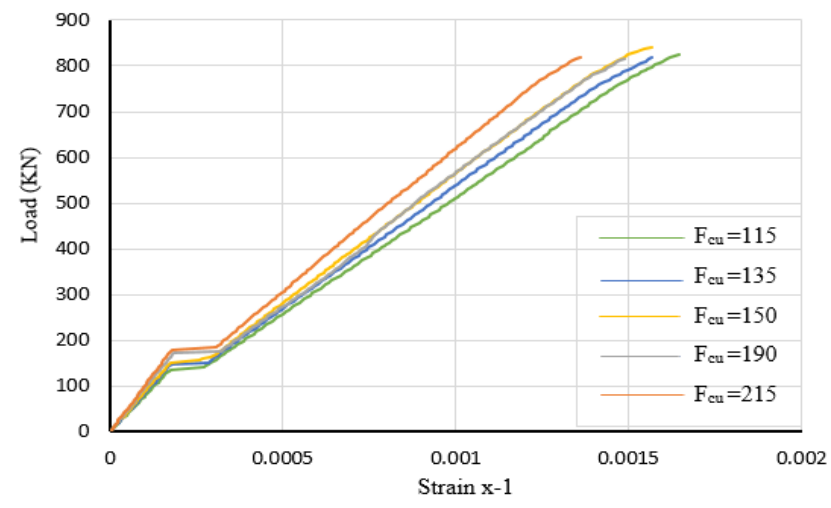

Figure 19 Load-Midspan Compressive UHPC Strain Curve for $\mathrm{B}_{6}, \mathrm{~B}_{7}, \mathrm{~B}_{8}, \mathrm{~B}_{9}$ and $\mathrm{B}_{10}$

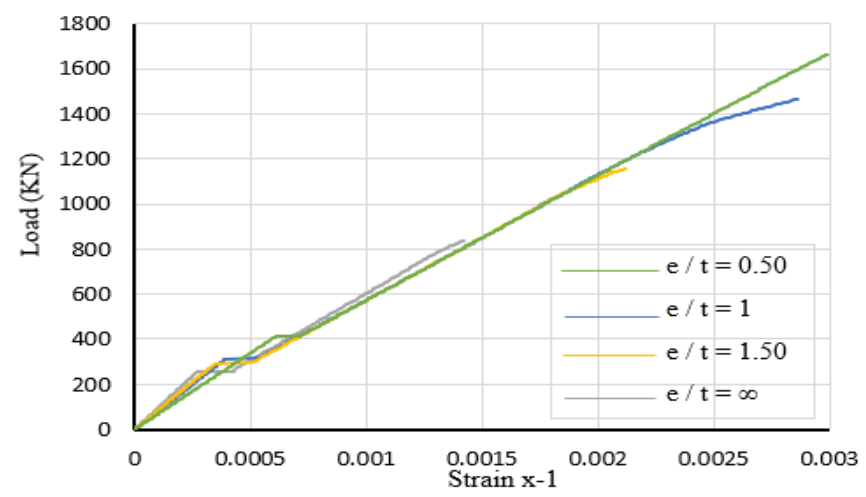

Figure 20 Load-Midspan Compressive UHPC Strain Curve for $\mathrm{B}_{11}, \mathrm{~B}_{12}, \mathrm{~B}_{13}$ and $\mathrm{B}_{\mathrm{o}}$

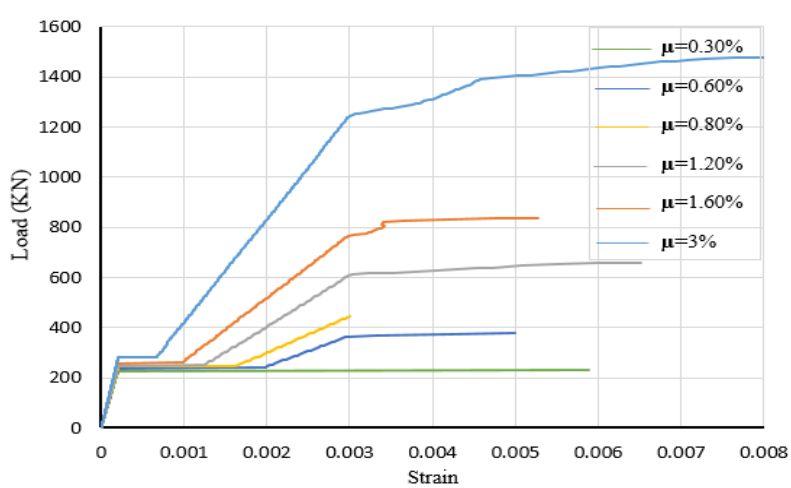

Figure 21 Load-Midspan Tensile Steel UHPC Strain Curve for $\mathrm{B}_{1}, \mathrm{~B}_{2}, \mathrm{~B}_{3}, \mathrm{~B}_{4}, \mathrm{~B}_{\mathrm{o}}$ and $\mathrm{B}_{5}$

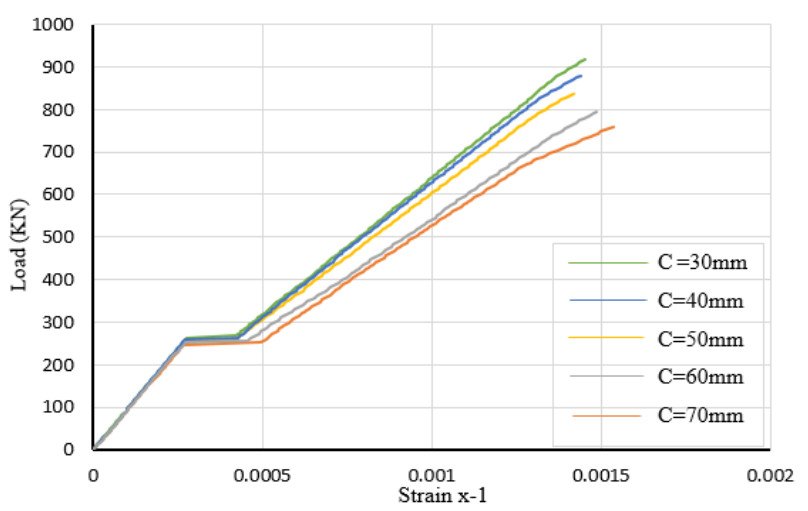

Figure 22 Load-Midspan Compressive UHPC Strain Curve for $\mathrm{B}_{14}, \mathrm{~B}_{15}, \mathrm{~B}_{0}, \mathrm{~B}_{16}$ and $\mathrm{B}_{17}$ 


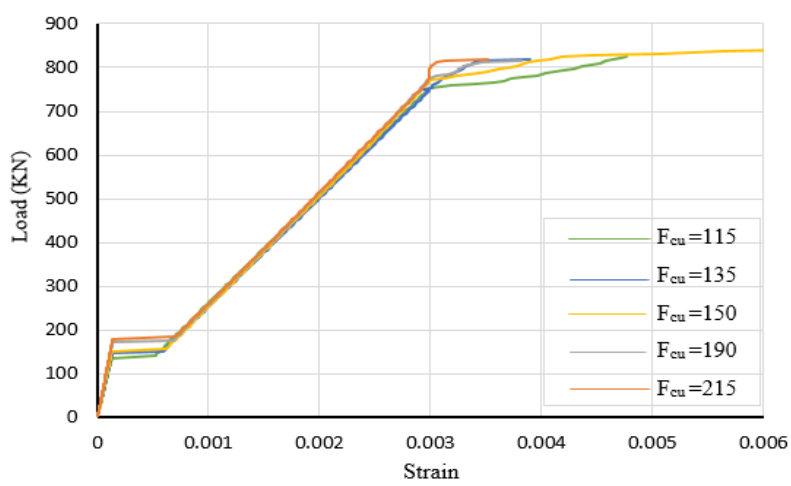

Figure 23 Load-Midspan Tensile Steel UHPC Strain Curve for $\mathrm{B}_{7}, \mathrm{~B}_{8}, \mathrm{~B}_{9}, \mathrm{~B}_{10}$ and $\mathrm{B}_{11}$

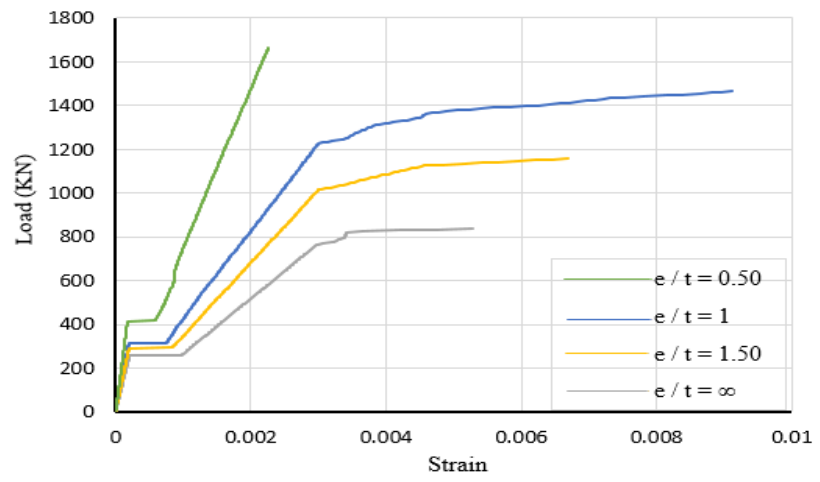

Figure 24 Load-Midspan Tensile Steel UHPC Strain Curve for $\mathrm{B}_{12}, \mathrm{~B}_{13}, \mathrm{~B}_{14}$ and $\mathrm{B}_{5}$

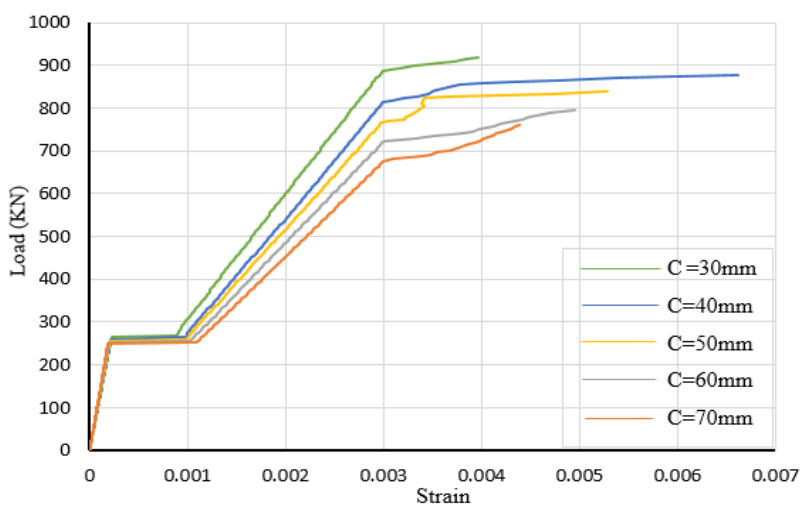

Figure 25 Load-Midspan Tensile Steel UHPC Strain Curve for $\mathrm{B}_{15}, \mathrm{~B}_{16}, \mathrm{~B}_{5}, \mathrm{~B}_{17}$ and $\mathrm{B}_{18}$

\section{DISCUSSION OF THE RESULTS}

$\mathrm{B}_{1}$ with $0.3 \%$ reinforcement ratio was yielded and failed after cracking directly to lack of reinforcement. The flexure capacity and stiffness at failure were influenced significantly and increased by increasing the reinforcement ratio. Increasing the reinforcement ratio by 100 , 166, 300, 433 and $900 \%$ led to increase the flexure capacity by 63, 91, 159, 261 and $541 \%$ compare to $\mathrm{B}_{1}$ with $0.3 \%$ reinforcement ratio. Increasing the reinforcement ratio by 100,166 , 300, 433 and $900 \%$ led to increase the stiffness by 52.1, 54.6, 95.6, 113.7 and $173.1 \%$ compare to $\mathrm{B}_{1}$. Increasing the reinforcement ratio led to restrict the extension of most of the cracks.

The ductility wasn't influenced by increasing the reinforcement ratio from 0.3 to $0.8 \%$. The ductility was influenced slightly and increased by increasing the reinforcement ratio from 0.8 to $3 \%$ by $40 \%$. The compressive UHPC strain at failure was influenced and increased by increasing the reinforcement ratio from 0.3 to $3 \%$ by $227.6 \%$. The compressive UHPC strain 
achieved 15.5, 18.6, 20.9, 27.1, 31.6 and $50.9 \%$ for reinforcement ratio 0.3, 0.6, 0.8, 1.2, 1.6 and $3 \%$ respectively compared to the ultimate strain of UHPC with $4500 \mu \varepsilon$. The tensile steel strain at failure wasn't influenced by changing the reinforcement ratio.

The flexure capacity wasn't influenced and showed the same behavior by increasing the compressive strength. While, the stiffness was influenced slightly and increased by increasing the compressive strength from 115 to $215 \mathrm{MPa}$ by $9.32 \%$. Increasing the compressive strength hadn't clear effect on the crack pattern. The ductility wasn't influenced by changing the compressive strength. The compressive UHPC strain at failure was influenced slightly and decreased by increasing the compressive strength from 115 to $215 \mathrm{MPa}$ by $17.5 \%$. The tensile steel strain at failure wasn't influenced by changing the compressive strength.

The flexure capacity was influenced and decreased by increasing the e / t ratio from 0.50 to $\infty$ by $49.7 \%$. The stiffness at the failure state was influenced significantly and decreased by increasing the e / $\mathrm{t}$ ratio from 0.50 to 1 by $40.6 \%$ and decreased slightly by $9.8 \%$ by increasing the e / t ratio from 1 to $\infty$. Increasing the eccentricity ratio from 1 to 1.5 and $\infty$ hadn't clear effect on the crack pattern. The ductility was influenced and decreased by increasing the eccentricity ratio from 1 to $\infty$ by $19.6 \%$. The compressive UHPC strain at failure was influenced and decreased by increasing the eccentricity ratio from 0.5 to $\infty$ by 52.5 $\%$. The tensile steel strain at failure was influenced and decreased by increasing the eccentricity from 1 to $\infty$ by $67 \%$.

The flexure capacity and stiffness at failure were influenced and decreased by increasing the cover from 30 to $70 \mathrm{~mm}$ by $17.2 \%$ and by $30.6 \%$. Increasing the concrete cover hadn't affect the crack pattern. The ductility was influenced slightly and increased by increasing the concrete cover from 30 to $70 \mathrm{~mm}$ by $13.1 \%$. The compressive UHPC strain at failure wasn't influenced by changing the concrete cover. The tensile steel strain at failure was influenced and decreased by increasing the concrete cover from 40 to $70 \mathrm{~mm}$ by $33.6 \%$. All beams were yielded and failed after yielding expect $\mathrm{B}_{11}$ with eccentricity ratio 0.5 failed before yielding at compressive zone. So, the failure was ductile for all beams expect $\mathrm{B}_{11}$ was brittle.

\section{CONCLUSIONS}

This paper presented a numerical study on the uniaxial flexural behavior of ultra high performance concrete beams. The most important conclusions of the conducted parametric study can be summarized as follows:

- Increasing the reinforcement ratio from 0.3 to $3 \%$ led to increase in flexure capacity by $541 \%$ and stiffness by $173 \%$. The crack pattern was enhanced. The ductility was increased by $40 \%$. The compressive concrete strain at failure was increased by 227.6 $\%$ and achieved $50.9 \%$ from the ultimate strain of UHPC. The failure was ductile till $3 \%$.

- Increasing the compressive strength from 115 to $215 \mathrm{MPa}$ led to increase in stiffness by $9.32 \%$. While, the flexure capacity wasn't affected. No effect on the crack pattern and the ductility. The compressive concrete strain was decreased by $17.5 \%$.

- Increasing the eccentricity ratio (e/t) from 0.50 to $\infty$ led to decrease in flexure capacity by $49.7 \%$ and stiffness by $49.8 \%$. The ductility was decreased by $19.6 \%$ for e/t equal to 1 till $\infty$. The compressive concrete strain was decreased by $52.5 \%$. The failure was ductile from e/t equal 1 to $\infty$ and brittle for e/t equal to 0.50 .

- Increasing the Concrete Cover from 30 to $70 \mathrm{~mm}$ Led to Decrease in Flexure Capacity by $17.2 \%$ and Stiffness by $30.6 \%$. The Ductility was Increased by $13.1 \%$. The Compressive Concrete Strain wasn't Affected by the Concrete Cover. 


\section{REFERENCES}

[1] Association Française de Génie Civil (AFGC), "Ultra High Performance Fibre-Reinforced Concretes- Interim Recommendations," 2002.

[2] Roth, M. J, Boone, N. R, Kinnebrew, P. G, Davis, J. L, Rushing, T. S, "Development of New Protective Solutions to Counter Emerging and Adaptive Threats," 2008.

[3] Bratislav Lukic', Pascal Forquin, "Experimental characterization of the punch through shear strength of," pp. 34-45, 2016.

[4] Richard, P, M. Cheyrezy, "Composition of Reactive Powder Concretes," Cement and Concrete Research, pp. 1501-1511, 1995.

[5] Jungwirth, J, A. Muttoni, "Structural Behavior of Tension Members in UHPC," École Polytechnique Fédérale de Lausanne, 2004.

[6] Rossi, "Development of New Cement Composite Materials for Construction," Proceedings of the Institution of Mechanical Engineers, Part L: Journal of Materials: Design and Applications, pp. 67-74, 2005.

[7] Duy-Liem Nguyen, Duc-Kien Thai , Tri-Thuong Ngo , Tuan-Kiet Tran , Tri-Thong Nguyen , "Weibull modulus from size effect of high-performance fiber-reinforced concrete under compression and flexure," Construction and Building Materials, p. 743758, 2019.

[8] Doo-Yeol Yoo, Soonho Kim , Jae-Jin Kim, Booki Chun, "An experimental study on pullout and tensile behavior of ultra-high performance concrete reinforced with various steel fibers," Construction and Building Materials, pp. 46-61, 2019.

[9] Doo-Yeol Yoo, Su-Tae Kang, Young-Soo Yoon, "Enhancing the flexural performance of ultra-high-performance concrete using long steel fibers," Composite Structures, 2016.

[10] In Hwan Yang, Changbin Joh, Byung-Suk Kim,"Structural behavior of ultra high performance concrete beams subjected to bending" Engineering structures, pp. 3478-3487, 2010.

[11] M.M. Kamal, M.A. Safan, Z.A. Etman, R.A. Salama, "Behavior and strength of beams cast with ultra high strength concrete containing different types of fibers," Housing and Building National Research Center, pp. 55-63, 2014.

[12] Venkatesh Kodur, Roya Solhmirzaei, Ankit Agrawal, Esam M Aziz, Parviz Soroushian, "Analysis of flexural and shear resistance of ultra high performance fiber reinforced concrete beams without stirrups," Engineering Structures, pp. 873-884, 2018.

[13] M. Singh , A.H. Sheikh, M.S. Mohamed Ali, P. Visintin, M.C. Griffith, "Experimental and numerical study of the flexural behaviour of ultra-high performance fibre reinforced concrete beams," Construction and Building Materials, pp. 12-25, 2017.

[14] M. Ala Saadeghvaziri, "Nonlinear response and modelling of RC columns subjected to varying axial load," vol. 19, no. 6, pp. 417-424, 1997.

[15] M.A. Al-Osta, M.N. Isa , M.H. Baluch, M.K. Rahman, "Flexural behavior of reinforced concrete beams strengthened with ultra-high performance fiber reinforced concrete," Construction and Building Materials, p. 279-296, 2017.

[16] Mohamadreza Shafieifar, Mahsa Farzad, Atorod Azizinamini, "A comparison of existing analytical methods to predict the flexural capacity of Ultra High Performance Concrete (UHPC) beams," pp. 10-18, 2018.

[17] Jie Wei, Jun Li, Chengqing Wu, "An experimental and numerical study of reinforced conventional concrete and ultra-high performance concrete columns under lateral impact loads," Engineering Structures, 2019. 
Wael M. Montaser, Ayman Hussein Hosny Khalil and Ahmed A. Abdel-Bary

[18] Ansys mechanical manual version 2018.

[19] Anis Mohamad Ali, Bj. Farid And A.I.M. Al-Janabi, "Stress-Strain Relationship for Concrete in Compression Madel of Local Materials," JKAU, vol. 2, pp. 183-194, 1990.

[20] Doo-Yeol Yoo, Young-Soo Yoon , "Structural performance of ultra-high-performance concrete beams with different steel fibers," Engineering Structures, pp. 409-423, 2015.

[21] Sung-woo Shin, Hoon Kang, Jong-mun Ahn, Do-woo Kim , "Flexural capacity of singly reinforced beam with $150 \mathrm{MPa}$ ultra high-strength concrete," Indian Journal of Engineering \& Materials Sciences, pp. 414-426, 2010.

[22] Yinghua YE, Song HU, Bo DAIO, Songlin YANG, Zijian LIU, "Mechanical behavior of ultra-high performance concrete reinforced with hybrid different shapes of steel fiber," ASCE, pp. 3017-3028, 2012. 